\title{
Rewarding Poverty Alleviation: A Case Study in Payment-by-Results
}

\author{
12 August 2019
}

Richard Sedlmayr

Payment-by-Results $(\mathrm{PbR})$ involves funders' commitments to make future grant payments as a function of yet-unachieved results. Though the justification may go beyond the desire to overcome incentive problems (such as moral hazard or adverse selection), it is desirable for payments to be closely tied to impacts - "as if" to incentivize implementers to perform in the interests of program beneficiaries. We describe a so-called impact bond transaction in the poverty alleviation space that commits payments in direct proportion to the economic value created in beneficiary households. Even so, incentive-compatibility is not easily achieved in practice: when funders insure themselves against extreme outcomes, and when working capital providers absorb performance risk, they alter the shape of the reward function. The greater the error associated with impact measurement, the more incentives can be affected.

Keywords: results-based financing, outcome funding, external validity, aid effectiveness

Author Affiliation: + Blavatnik School of Government and St Antony's College, University of Oxford. richard.sedlmayr@sant.ox.ac.uk.

Transparency Statement: Supplementary materials, data, and code are accessible on the Open Science Framework (osf.io/mp5ns).

Disclosures: My involvement in project design and donor advisory could have affected the neutrality of my assessments.

Acknowledgments: This work was prepared in the context of an ongoing project involving multiple parties. It could not have emerged without the thought partnership of Avnish Gungadurdoss, Douglas Emeott, and Juan Camilo Villalobos of Instiglio, a nonprofit organization that promotes results-based financing in development and has the overall responsibility for the management of the project. I thank Dianne Calvi, Celeste Brubaker, and Caroline Bernadi at Village Enterprise; Jessica Cartwright and Radana Crhova at the UK Department for International Development; Duc Tran and Joaquin Carbonell at the US Agency for International Development; and Wesley Panek and Alice Gugelev at Global Development Incubator. I also benefitted from relevant interactions with Stefan Dercon, Mushfiq Mobarak, Jan Witt, Bill Savedoff, Owen Barder, James Snowden, Celeste Brubaker, Mara Arioldi, Julien Labonne, Martin Williams, and Bruce Wydick. Any errors are mine. 


\section{INTRODUCTION}

There is long-standing interest in the use of $\mathrm{PbR}$ mechanisms to enhance the effectiveness of development assistance (Savedoff, Perakis, \& Schwanke, 2016). Following initial experiences in the United Kingdom, the concept of impact bonds has been gaining traction in development space (Floyd, 2017; Social Finance, 2019). These typically make results-based payments to non-governmental implementers and involve private investors to help bridge working capital gaps (Fraser, McHugh, \& Warner, 2019). We will first conceptually review the justifications and pitfalls associated with $\mathrm{PbR}$, then present a case study involving an impact bond aimed to alleviate poverty in Uganda. We will then contextualize the justifications and pitfalls in the Ugandan case; for this purpose, we will simulate outcomes and payments using available pre-existing evaluation data.

\section{CONCEPTUAL ANALYSIS OF PBR}

\section{Justifications}

A fundamental problem of charitable aid transactions is that the benefits are not meant to accrue to the grantor (funder) nor the grantee (implementer), but to third parties that typically get to participate in the resource allocation process neither as market players nor as voters. This calls for rules and procedures to assure that the interests of the intended beneficiaries are accounted for. There are different ideas for to achieve this (though they do not claim to be universal, final, or mutually exclusive). For example, one prescription is to disburse resources directly as cash to beneficiaries to allow them to act upon their own preferences (Blattman \& Niehaus, 2014). Another holds that interventions should be administered with enough granularity to allow for the identification of causal effects, which can then be used to adapt the development sector for the better by accelerating effective approaches and dropping ineffective ones (Banerjee, Deaton, Lustig, Rogoff, \& Hsu, 2006; Banerjee \& Duflo, 2011). Meanwhile, PbR prescribes 
that funders pay implementers directly as a function of outcomes, thereby creating accountability for impact (Savedoff et al., 2016).

\section{Asymmetric Information Frame}

Justifications for PbR often invoke the need to create appropriate incentives for implementers. This implies that funders have information gaps about an implementer's true capability or effort (Clist, 2016; Lazear, 2003).

Moral hazard problems may arise when the principal (the funder) lacks information about some hidden actions of an agent (say, about the amount of effort exerted by an implementer), and when the incentives of principals and agents differ (say, because the implementer values comfort). In this framework, PbR can be viewed as "performance pay" to align the agent's incentives with the objectives of the principal.

A variant of the principal-agent problem can arise when a market player's offer attracts a counterparty with undesirable traits on a hidden dimension. Let us posit that most implementers are in fact motivated to serve the poor as best they can, but have diverse beliefs sets about the proper approach to solving a problem. Among them, one bad apple is unconcerned with social impact and instead concerned with raising money to perpetuate its own existence and therefore willing to uncritically align its narratives with the beliefs of funders. If funders are naïve about this and fund only based on the alignment of an applicant's funding application with their own beliefs, then in a form of adverse selection the "narrative entrepreneur" will be selected for funding. Meanwhile, if funders are aware of their predicament, they can use $\mathrm{PbR}$ as a signaling device to encourage the self-selection of "impact entrepreneurs" who intend to execute a course of action that they truly believe to be sensible.

\section{Knowledge Gap Frame}

Both moral hazard and adverse selection are grounded in the principal-agent model. In framing the interests of implementers - but not funders - as misaligned with those of beneficiaries, this model builds on a questionable foundation. It can be sensible to assume that implementers and funders are equally motivated 
to achieve their stated objectives: altruism (and complementary desires for reputation and self-respect) are well-established drivers of human behavior that can dominate nonsocial incentives (Batson \& Shaw, 1991; Fehr \& Fischbacher, 2003; Ashraf, Bandiera, \& Jack, 2014). Even so, PbR can remain sensible: it has the potential to trigger learning processes that overcome shared ignorance about how to achieve impact.

Translating evidence into policy comes with many difficulties. The body of accessible evidence may be biased, ${ }^{1}$ and effects that emerged in different contexts may be moderated by unknown factors. ${ }^{2}$ Even evidence that is both credible and context-relevant is not easily acted upon, e.g., because of skill and attention deficits (Callen, Khan, Khwaja, \& Liaqat, forthcoming). PbR has the potential to draw decisionmakers' limited attention to contextually relevant evidence of impact (Perakis \& Savedoff, 2015). The role of funders is to focus on "ends": PbR forces them to realistically establish their willingness to pay for social outcomes based on the opportunity costs of capital. Meanwhile the role of implementers is to identify appropriate "means" and focus on the challenge of delivering impacts with limited resources. Both the impact and the cost drivers of cost-effectiveness therefore receive appropriate consideration. At the

\footnotetext{
${ }^{1}$ For instance, there may be selection bias in favor of evaluation sites where conditions are unusually favorable in the first place. Useful evidence can then only be retrieved from sites where implementation succeeds, introducing survivorship bias. This is aggravated by publication bias driven by the norms and incentives of academia (Ioannidis, 2005). Research outlets may elevate results that are significant, intuitive, or entertaining, and direct less attention towards results that are insignificant or perplexing. In anticipation of such biases in the publication process, researchers may mine for those analytical specifications that happen to yield welcome results and deprioritize the reporting of less compelling ones, further skewing the body of evidence. There are indications that experimental results tend to be less biased by statistical reporting conventions than nonexperimental ones, though they are not immune (Brodeur, Sangnier, Lé, Sangnier, \& Zylberberg, 2016; Chan, Hrobjartsson, Haahr, Gotzsche, \& Altman, 2004).

${ }^{2}$ Even methods that go to great lengths to identify causality in a given setting (such as randomized evaluations, which subject the entire implementation process to scientific protocol) may not provide any elevated insight into the factors that moderated the impacts. Generalizing from past evaluation results calls for an awareness of the contextual factors that moderated effects in the original settings, and of their role in the new and different settings (Cartwright \& Hardie, 2012; Deaton, 2010). Without such awareness, it is difficult to extrapolate into new settings where moderators may differ, and difficult to cumulate evidence into a body of knowledge. A theoretical grasp of the barriers to progress, and of the mechanisms through which interventions unfold impact, is said to be required for the appropriate use of evidence in policymaking (Bates \& Glennerster, 2017; Williams, 2017).
} 
conclusion of a project, evidence of impact becomes the central determinant of payment streams and is certain to become top-of-mind for all parties involved.

Some forms of knowledge are inherently difficult to codify, diffuse, and learn. For example, implementers may accumulate tacit "know-how" (Polanyi, 1966) and diverse subtle, nuanced, and fleeting insights as they "muddle along" in trial-and-error (Andrews, Pritchett, \& Woolcock, 2013). PbR can accommodate this by affording implementers the flexibility to mutate their approach (Savedoff et al., 2016) and then selecting for successful approaches in an evolutionary fashion (Barder, 2012). ${ }^{3}$ For intuition, assume that funders and implementers are unable to use evidence for projection, and indeed altogether unable to form any expectations at all. Picture implementers as the equivalent of a basic biological organism that obstinately executes a given programmatic code, and funders as the equivalent of a natural selection mechanism that retrospectively rewards resources to those implementers that happen to find success. To the extent that these resources tend to propagate the success factors in the implementer's programmatic code, we have a system that could force the constituency of the development sector to be a successful one. The long-term repercussions will depend on specific assumptions about this propagation process. For instance, if we assume a stable set of implementers with immutable programmatic code, the unit of selection is the implementer: successful implementers will start to outgrow unsuccessful ones and start to dominate the sector. Meanwhile, if we assume that success leads to the replication of the successful implementer's programmatic code outside of the implementer's structures, the implementer would (using the terminology of Dawkins, 1976) merely be a vehicle, while the programmatic code (e.g., the active

\footnotetext{
${ }^{3}$ Such forces are known to operate well beyond the domain of biology; they are often invoked in the discussion of technological change and economic progress (Beinhocker, 2007; Lynch, 1996; Nelson \& Winter, 1982; Schumpeter, 1942 ) and are actively deployed in the domain of machine learning and artificial intelligence (Barto \& Sutton, 1998). Evolutionary and incentive-based perspectives can often be reconciled as complementary scientific models of the same phenomena. Biologist Mayr (1961) argued that it is simultaneously true that a predator's hunt is caused by hunger and by natural selection; one can be seen as a "proximate" and the other as an "ultimate" cause. Economist Friedman (1953) illustrated the breadth of incentive-based argumentation by proposing that leaf canopies are shaped "as if" trees deliberately strived to maximize exposure to sunlight.
} 
ingredients of the implementer's approach that caused success) would be the replicator. This evolutionary framing speaks to difficulties associated with the generalization of evidence. Even if both funders and implementers were overwhelmed by the complexity of projecting where effectiveness will materialize, a results-based funding system might select for effectiveness and thereby learn by reinforcement.

\section{Concerns}

There are numerous concerns about unwelcome aspects and unintended consequences of $\mathrm{PbR}$. (For a detailed discussion, see Clist, 2016):

\section{Costs}

$\mathrm{PbR}$ introduces contractual complexities not found in other arrangements. For instance, impact evaluation is no longer a luxury but required as a matter of routine. As specific evaluation results get directly tied to the financial standing of specific stakeholders, corrupting forces could threaten the independence of evaluation. Furthermore, as $\mathrm{PbR}$ removes the presumption of strategic alignment, the transacting parties may be more inclined to make zero-sum investments to prepare for or engage in disagreements (Eldridge \& Tekolste, 2016).

When payments are made retrospectively based on demonstrated results, this also creates the need for working capital to support program execution in the interim. Such capital is subjected to performance risk, as it is repaid as a function of results that are not established at the time of investment. The implementers of development programs are frequently small nonprofit organizations that may not have such risk capital readily accessible. So-called impact bonds provide a conceptual and administrative framework to enable private risk capital providers to invest in the activities of nonprofits. The term "impact bond" is a misnomer because such arrangements rarely involve fixed interest commitments that would subject the investee to the risk of default; payments are often defined as a function of program results and performance risk is transferred to the investor. 
To the extent that investors require positive expected returns to compensate them for the time value and risk associated with their investments, part of the total envelope of social resources available for development efforts is absorbed by the financial sector. Our concern about this will depend on our assumptions about the efficiency of financial markets: if capital is efficiently priced, outcome funders value their risk reductions no less than the investors charge for absorbing them. Indeed, if we assume that there is dormant investor demand for so-called impact investments and that the expected returns from such investments are below the risk-adjusted market rates, then impact bonds might attract additional net capital towards development challenges. But adding investors to the already complex PbR arrangements can be costly; the transaction costs of joint ventures have been shown to grow exponentially with the number of contracting parties (Gong, Shenkar, Luo, \& Nyaw, 2007). At the time of writing, even after the initiation of dozens of impact bonds over the last seven years amounting to hundreds of millions of dollars in transaction volume, philanthropic subsidies to the origination process remain the norm (Floyd, 2017).

\section{Potential for Motivation Crowding Effects}

Performance pay can crowd out the payee's intrinsic motivation of agents by undermining the presumption of mutual trust that can otherwise govern the execution of incomplete contracts (Bénabou \& Tirole, 2006; Falk \& Kosfeld, 2006a; Frey, 1997). Indeed, it has been argued that PbR is not an evidence-based approach because it appears to defy empirical insights on the effects of extrinsic performance incentives on intrinsic motivation (Frey, 2017). Of additional concern, there is evidence to suggest that once a social contract is damaged through the introduction of an ill-conceived pecuniary incentive, it may not be restored through the subsequent removal of the incentive (Gneezy \& Rustichini, 2000).

\section{Potential for Gaming}

Goodhart's law holds that incentive processes can corrupt measures once they are defined as targets, as intuitively illustrated by anecdotes that bounties on pests that were meant to control them instead encouraged their breeding (Campbell, 1979; Goodhart, 1975; Vann, 2003). Short of entirely backfiring, 
target-setting can skew a multitasking implementer's priorities towards those activities whose success is most easily measured, dis-incentivizing ones that may be equally valuable but more difficult to measure (Holmstrom \& Milgrom, 1991). It may also lead to cream-skimming, encouraging the exclusion of beneficiaries that are perceived as costly (McHugh, Sinclair, Roy, Donaldson, \& Huckfield, 2013). The perverse effects of performance incentives have been widely established in public policy contexts (Carter \& Whitworth, 2015; Courty \& Marschke, 2008; Dixit, 2002; Jacob \& Levitt, 2003).

\section{CASE STUDY: THE VILLAGE ENTERPRISE IMPACT BOND}

\section{Background}

Village Enterprise is a small non-profit organization that was funded in 1987 and has an annual operating expense budget between US\$1.2M (2013) and US\$2.1M (2016). Most of this is spent on the implementation of microenterprise programming in rural regions of Uganda and Kenya. The intervention has been filed under the ultra-poor graduation program label, as it shares the key aspects of its objective and approach: Village Enterprise targets the poorest households (ordinarily between the poorest quartile and the poorest half of a given village, as measured through a participatory wealth ranking and validated through a simple survey) and provides them with a seed asset as well as an intangible human capital asset (generated through an extended series of training and mentorship sessions). The theory of change holds that the intangible asset helps households maintain their newly acquired wealth and apply it to productive activities, deriving economic value from it. This is thought to generate a stream of income and sustained improvements in living standards as a result.

The program has some distinctive features. It involves the formation of both business groups (target size: three households) and savings groups (target size: 30 households). The seed asset is provided in the form

of cash - more specifically, two cash injections to the business group. The program is less intensive than 
many of the so-called graduation programs that share its spirit: it comes at roughly a third of the cost (in USD PPP terms) of the least costly one of those evaluated in the meta-study of Banerjee et al. (2015).

Between 2013 and 2016, the implementer was involved in a randomized trial evaluating the impacts of diverse components and variants of its program (Sedlmayr, Shah, \& Sulaiman, 2018). Results suggest that the implementer succeeded in reducing poverty.

As the implementer is relatively small but has demonstrated the potential and ambition to scale up, it is an interesting case to study the process of promoting integrated poverty alleviation through $\mathrm{PbR}$. A group of funders decided to support an expansion of its programming with an outcome funding commitment that would allow the implementer to reach roughly $15 \mathrm{k}$ households ( $\sim 90 \mathrm{k}$ individuals). Rather than projecting with confidence that specific rates of cost-effectiveness will be achieved in the future, funders offered to reward the implementer as a function of future impacts.

The challenge was framed as follows: "As the deepening body of evidence points to the potential of integrated poverty alleviation interventions, priorities shift to a new challenge: how to administer them cost-effectively at growing scale? Funders recognize their own limitations in grasping the necessary success factors and challenge entrepreneurially minded development practitioners to master and demonstrate cost-effective delivery."

\section{Design, Implementation, and Measurement}

The details of the challenge are as follows. ${ }^{4}$ As illustrated in Figure 1, donor-funders contribute to a single trust (the "Poverty Alleviation Outcomes Fund") which escrows them and prepares a Payment-by-Results contract with the implementer. The implementer does not have to be fully financed at this point; it has the option to use the contractual commitment to independently raise any working capital necessary to

\footnotetext{
${ }^{4}$ For a more detailed illustration, see the design memo by Instiglio (2018).
} 
implement the project. All contracts would remain bilateral: none would be signed by more than two parties.

\section{Figure 1: Contractual Framework}

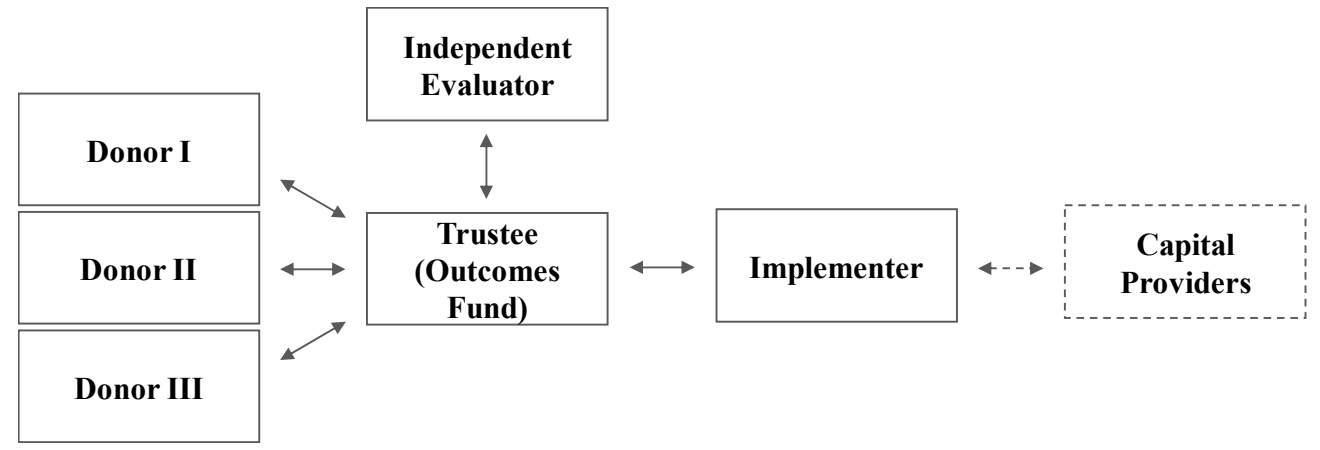

Note: Arrows depict contractual relationships.

Enough funding was initially committed to support outcome payments for seven cohorts (see Figure 2), each comprised of 28-66 villages where measurement would take place. Once financed, the implementer would generate a list of targetable villages, identify eligible households in these villages using its ordinary targeting mechanisms, and provide these data to the independent evaluator. The evaluator would randomize units into a treatment and a control group and return the list to the implementer, who would proceed to implementing the program with treatment participants and commit to not engaging with control participants any further. 
Figure 2: Implementation Sequence (Treatment Group)

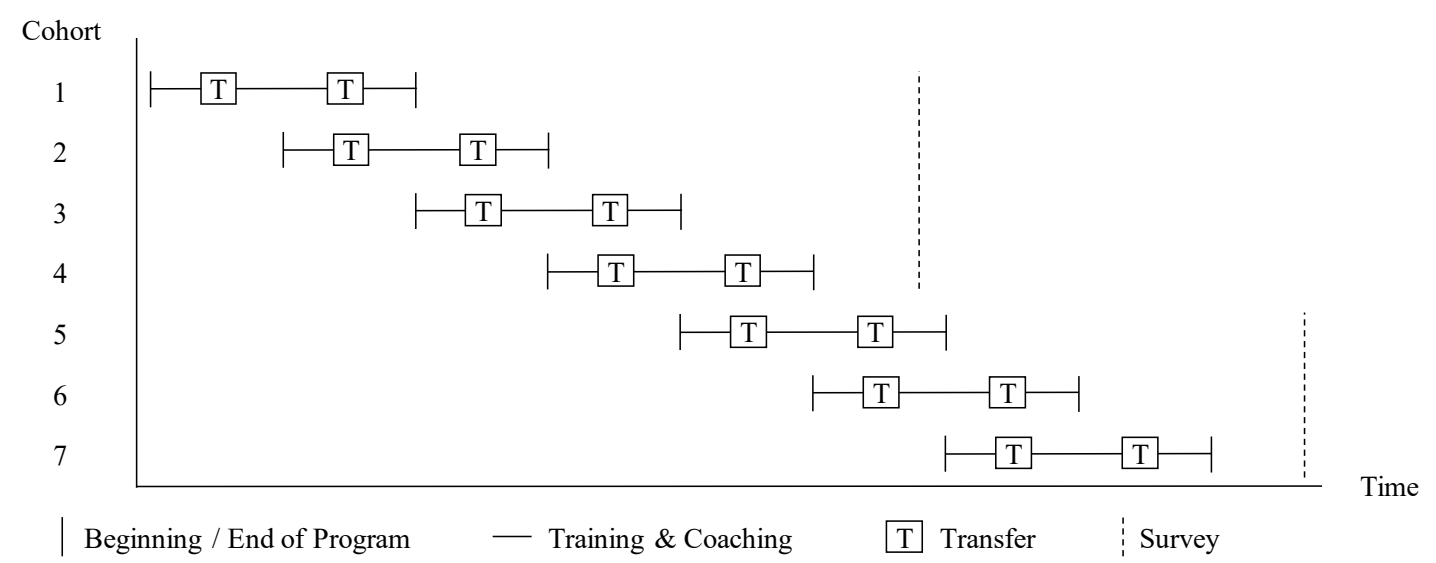

The provision of seed assets (in the form of two cash transfers) is a central feature of the program, and the evaluator would independently confirm if and exactly when each transfer is provided to each eligible beneficiary. This involves a validation exercise: the independent evaluator assigns enumerators to be physically present at the disbursements to document all transfers.

The evaluator would conduct one household survey in treatment as well as control villages, collecting data on asset stocks and consumption flows. In consideration of a trade-off between survey costs and capital costs, cohorts 1 through 4 and 5 through 7 would be surveyed jointly.

Note that not all recipient households would receive transfers, or get surveyed, at precisely the same time; nor will all achieve the same incremental outcomes. The payment function processes impact estimates not at the level of households but on the basis of averaged values. In effect, the analysis would therefore be conducted on behalf of the representative beneficiary: a hypothetical household in the treatment group who experiences impacts corresponding to the intent-to-treat effect. Village Enterprise would be compensated 
for the effects experienced by this representative beneficiary, multiplied by the number of targeted beneficiaries. $^{5}$

As described in Figure 3, period 0 is the date when the transfer is provided to the representative treatment participant. Period $m$ is when the participant answers the household survey, which takes place several months after implementation concludes for the last beneficiary in the set and approximately two years after the weighted transfer date ${ }^{6}$ of the representative beneficiary.

\section{Figure 3: Measures Extracted for the Representative Beneficiary}

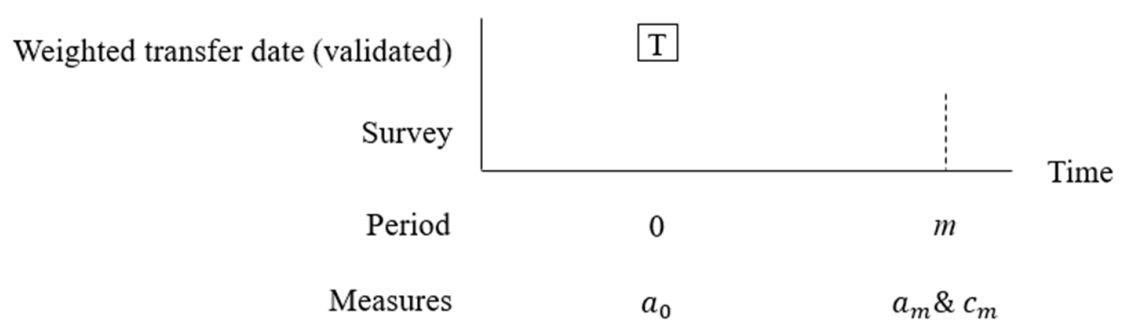

The following values ${ }^{7}$ would be estimated for the representative participant:

$m$ : The number of months elapsed between the weighted transfer date and the date of survey measurement.

$a_{0}$ : The incremental asset stock of the representative beneficiary in period 0 . This corresponds to the (average) sum of the two transfers, as established in the transfer validation data.

\footnotetext{
${ }^{5}$ In practice, values would be averaged across cohorts 1 through 4 and a payment calculated and disbursed for these upon conclusion of the initial survey; at the end of the final survey, values would be recalculated and payments would be trued-up.

${ }^{6}$ The weighted transfer date is defined as the date that corresponds to the average date of the two transfers, weighted by the two transfer amounts.

${ }^{7}$ All monetary values are defined in current US dollars at time of measurement.
} 
$a_{m}$ : The incremental net asset position at the time of the survey, i.e., the treatment effect on asset stocks in period $m$. The underlying data would be collected through a household survey that is conducted in both treatment and control villages.

$c_{m}$ : The incremental monthly consumption flow in the representative beneficiary household at the time of the survey, i.e., the average treatment effect on consumption in period $m$. This too is collected through the household survey.

The statistical significance of estimates would not be factored into the payment function. ${ }^{8}$

Using the above, a rate of change in asset impacts can be estimated. Assuming that $a_{m}>0$ and $a_{0}>0$, we can calculate an estimated monthly asset growth rate:

$$
\text { (I) } \quad g=\left(\frac{a_{m}}{a_{0}}\right)^{\frac{1}{m}}-1
$$

As incremental asset positions declined in the previous Village Enterprise trial, $g$ may well be negative. An important assumption in the forthcoming payment function will be that the growth rate of asset impacts approximates the growth rate of consumption. This assumes that the transfers are invested in tangible productive assets (such as livestock, inventory, and tools); and that the returns are consumed. It also assumes constant returns to scale - implausible across the production function but plausible at the margin.

\section{Payment Function}

The objective of the payment function is to create a demand schedule for outcomes that links payoffs to economic impact. The basic objective will be to compensate the implementer for the present value of

${ }^{8}$ The rationale for this is twofold: first, to simplify due diligence for any working capital providers; and second, to avoid introducing norms that would grant a systematic advantage to high-impact interventions over equally costeffective low-cost ones. 
consumption gains created. This compensation will be no lower than the total cash assets that the implementer transferred to the beneficiaries (a plausible lower bound on impact), and no higher than the volume of available outcomes funds (a necessary upper bound on payments).

As soon as the transfer would be validated, the incremental asset position at time 0 is known and the fund would already make payment $P_{0}$ to compensate the implementer for it: ${ }^{9}$

$$
\text { (II) } \quad P_{0}=a_{0}
$$

The choice of this early payment, based on an input-type measure, is grounded in the desire to mitigate working capital requirements and to focus the piloting of the Payment-by-Results mechanism on the intangible portion of the program, which may not be as easily scalable as the cash transfer portion. (That said, $a_{0}$ can be defended as an outcome measure because it constitutes a lower bound on the expected benefits of the cash asset: $a_{0}$ would equal its impact on consumption outcomes if it was immediately dissaved and consumed.)

The long-term results of the program (particularly those of the human capital portion, which accounts for the majority of the implementer's usual program costs) are not easily valued at the time of intervention, ${ }^{10}$ so the parties would wait to learn if additional payments are warranted. In period $m$, Payment $P_{0}$ would be clawed back and through lump sum payment $P_{m}$ redefined to something more closely resembling the net present value of incremental consumption:

$$
P_{m}=-a_{0}+c_{m} m+c_{m} x
$$

\footnotetext{
${ }^{9}$ In practice, both seed transfers to participants and corresponding payments from the outcomes fund will be disbursed sequentially. The weighted average transfer date should be considered period 0 .

${ }^{10}$ One creative approach might be to establish respondents' willingness to pay for human capital; see Shapiro (2017). It is however questionable if such assessments will be anywhere near accurate; see Jensen (2010).
} 
In summary, the first term on the right hand side is meant to capture the value of the seed asset, which is now returned and therefore subtracted. The second term approximates the value of accumulated incremental consumption that is estimated to have materialized in periods 1 through $m$. The third term approximates the value of projected incremental consumption beyond period $m . x$ is a multiplier that translates the incremental consumption flow into a perpetuity. By time $m$, there are three possible scenarios (A, B, and C) and corresponding multipliers:

\section{Scenario A: Incremental Assets Have Disappeared}

Assume (pessimistically) that by period $m$ no incremental asset position remains: $a_{m} \leq 0$ in this scenario. This implies that the asset which is critical to the theory of change has been consumed, and therefore does not warrant the expectation that a further stream of benefits will continue to accrue beyond period $m$. But it is possible that consumption effects are still discernible and that the estimated accumulated incremental consumption flow has already exceeded of the value of the asset. At minimum, $P_{m}$ accounts for these benefits, so the first two terms of Equation III remain intact. Therefore:

(IV) $x_{A}=0$

and:

(V) $\quad P_{m_{A}}=-a_{0}+c_{m} m$

\section{Scenario B: Incremental Assets Have Not Fallen}

It is expected that the implementer will aim to achieve a degree of sustainability that warrants a payment in excess of $P_{m_{A}}$. In an ideal case, asset impacts will have not fallen at all by period $m$, implying $a_{m} \geq a_{0}$. If so, it is assumed that the stream of incremental consumption benefits will at the very least persist $(g=$ 0 ). To value it, a periodic discount rate $\beta$ must be defined. The chosen discount rate of $10.00 \%$ annualized ( $\beta=0.80 \%$ compounded monthly) was selected to correspond to donors' perceived opportunity cost of capital. 
Therefore,

$$
\text { (VI) } \quad x_{B}=\frac{1}{\beta}
$$

and:

(VII) $\quad P_{m_{B}}=-a_{0}+c_{m} m+c_{m} \frac{1}{\beta}$

\section{Scenario C: Incremental Assets Have Diminished}

In the scenario that is considered most likely based on available evidence, asset impacts have neither fully persisted nor fallen to zero by period $m$, but are lower than the initial asset transfer has been: $a_{0}>a_{m}>$

0 . Given the theory of change, it is projected that consumption effects will also be declining in the future. As discussed above, the rate of asset growth can be measured using one validation exercise and one survey, and the rate of consumption growth is also assumed to equal rate $g$ - a negative number. Therefore:

$$
\text { (VIII) } x_{C}=\frac{1+g}{\beta-g}
$$

and:

$$
\text { (IX) } \quad P_{m_{C}}=-a_{0}+c_{m} m+c_{m} \frac{1+\mathrm{g}}{\beta-g}
$$

\section{Introduction of Caps and Floors}

Extreme values and payments are possible, and both funders and the implementer have grounds to worry about tail risks. $P_{m_{\text {floor }}}$ limits the downside risk for the implementer and $P_{m_{\text {cap }}}$ ensures that payments owed will not exceed the available outcome funds. Summing up, the "final" payment function $P_{m}=P_{m_{F}}$ shows the rule that would be executed in period $m$ :

$$
\text { IF } a_{m} \leq 0 \quad \rightarrow \text { THEN } P_{m_{F}}=\text { Median }\left[P_{m_{\text {floor }}}, P_{m_{A}}, P_{m_{\text {cap }}}\right]
$$


$(\mathrm{X})$

$$
\begin{aligned}
& \text { IF } \quad a_{m} \geq a_{0} \\
& \text { IF } \quad a_{0}>a_{m}>0
\end{aligned}
$$

$$
\begin{aligned}
& \rightarrow \text { THEN } P_{m_{F}}=\text { Median }\left[P_{m_{\text {floor }}}, P_{m_{B}}, P_{m_{\text {cap }}}\right] \\
& \rightarrow \text { THEN } \quad P_{m_{F}}=\text { Median }\left[P_{m_{\text {floor }}}, P_{m_{C}}, P_{m_{\text {cap }}}\right]
\end{aligned}
$$

\section{Subsequent Developments}

In the project at hand, the minimum and maximum bounds that were negotiated by donors and the implementer amounted to $P_{m}$ floor $=0$ and $P_{m_{\text {cap }}}=265$. Donors committed a total of USD $4.28 \mathrm{M}$ in outcomes funds to a nonprofit trustee organization ${ }^{11}$ and allocated additional funds to an independent evaluator. The trustee challenged the implementer to independently make any arrangements to unlock funds under the payment agreement described above. ${ }^{12}$

The implementer decided that it could use available working capital to implement the cash transfer portion of the program, which would be repaid quickly and could therefore be recycled across cohorts. Stating operational research purposes, it decided that it would slate two thirds of recipients to receive the traditional USD 50 transfer while one third would receive USD 150. It approached external investors with an agreement that would commit the implementer to use all external investments for the purpose of working capital needed for the non-cash components (i.e., the training and mentorship components as well as associated overhead) and to spend no less than USD 157.77 per household on this. If and once the outcomes fund was to make outcome payments $P_{m}$, the implementer would pass these payments to

${ }^{11}$ Two of the three funders transferred all resources to the trustee upfront. The third funder made pledges of future payments.

12 One condition was that donors would not compensate the implementer for more than USD $1.2 \mathrm{M}$ in the form payments $P_{0}$ (i.e., the reimbursement of cash transfers). 
investors after subtracting and retaining for itself half of any payments that amount to rates of return in excess of $0.57 \%$ compounded monthly $(7.00 \%$ compounded annually). Using this agreement, the implementer raised USD 2.325M from investors within six months.

\section{CONTEXTUALIZED ANALYSIS OF JUSTIFICATIONS}

As Village Enterprise has already demonstrated cost-effective poverty alleviation in a past trial by Sedlmayr et al. (2018), and this trial was not associated with outcome based payments, it appears unnecessary to introduce financial incentives to encourage the organization to perform. In other words, it appears implausible to justify the PbR project using the principal-agent model.

We discussed that an alternative objective could be to overcome fundamental knowledge gaps. How might this apply here? The Village Enterprise program is representative of so-called ultra-poor graduation programs that target the poorest households in low-income countries and offer them an integrated program involving transfers as well as customized training and mentorship in an attempt to help them establish sustainable microenterprises (Bandiera et al., 2017). Substantial research on such programs already exists. A meta-study by Banerjee et al. (2015) summarizes six randomized pilot studies of such interventions and indicates that sustained poverty relief is achievable across contexts. Even so, it is difficult to form expectations about the cost-effectiveness of future graduation-type programs, as there is heterogeneity in the results: the approach has been dramatically more cost-effective in some settings than others. Figure 4 presents benefit/cost metrics from the various evaluations that were reviewed in the meta-paper. 
Figure 4: Benefit/Cost Ratios in Six “Graduation" Sites

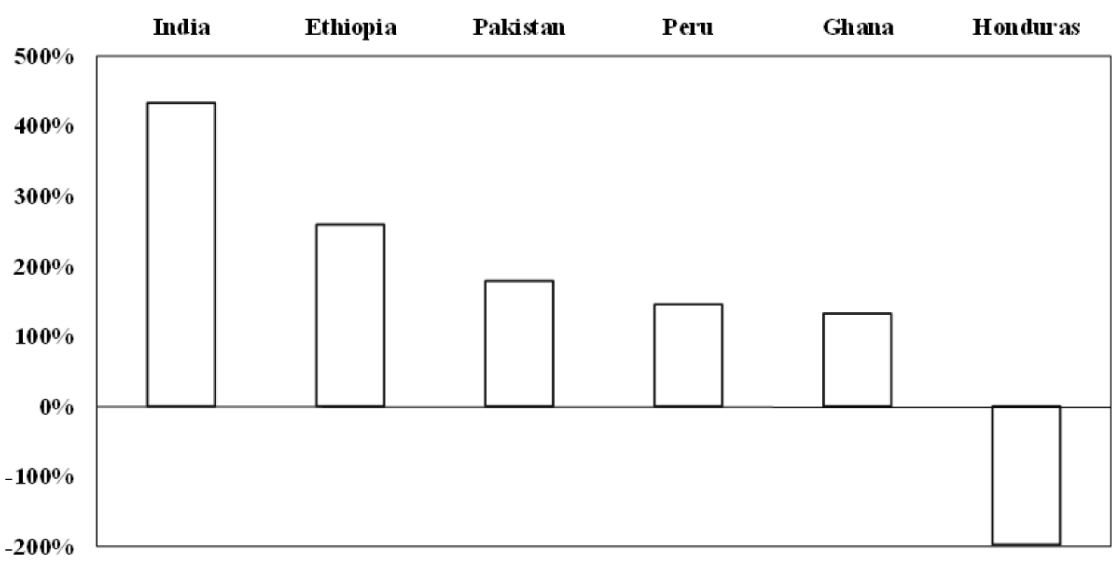

Note: For underlying assumptions, consult the data source: Banerjee et al. (2015).

The review discusses this heterogeneity. In the least successful site, the transferred tangible assets depreciated at high rates, which the authors interpret as an indication that the transfer component may be a necessary condition for graduation to succeed. But they do not claim that this is the only reason for the observed heterogeneity - with good reason: clearly there may be any number of other moderators. While we can venture an educated guess about some necessary conditions - e.g., the training and mentorship components will not likely be impactful if they are not implemented, or not delivered in the right language - we cannot readily determine what conditions will be sufficient for these interventions to achieve a given effect. The critical ingredient may be tacit "know-how" that is subtle and cannot be easily defined, measured, or monitored. There are indications that the success factors are present in the Village Enterprise program: in the past impact evaluation, rates of cost-effectiveness appeared high. In other words, the program is known to be efficacious - effective in principle. ${ }^{13}$ But there are grounds to ask if the implementer will maintain such cost-effectiveness at growing scale. Though we do know that it is possible for graduation-type programs to be implemented effectively at meaningful scale (Bandiera et al., 2017),

${ }^{13}$ Clinical and public health research uses the terms "efficacy" and "effectiveness" to distinguish between basic science trials and ones grappling with at-scale delivery; see Gartlehner, Hansen, Nissman, Lohr, \& Carey (2006). 
almost all evaluations - Village Enterprise included - took place in small-scale settings. It is reasonable to fear that the factors that moderate their impact may be correlated with the scale of implementation (Bold, Kimenyi, Mwabu, Ng'ang'a, \& Sandefur, 2013): e.g., that the fidelity and impacts may suffer with scale.

By engaging in $\mathrm{PbR}$, donors were able to circumvent the need for strong assumptions about what evidence will emerge as the approach advances to greater scale. They could simply define their perceived opportunity cost of capital and left it to the implementer to deliver. The expected rate of return of $10 \%$ corresponds closely to the median internal rate of return from past investments in graduation programs (i.e. 8.50\% annualized and in real terms; Banerjee et al., 2015; plus approximate USD inflation at the time of project origination.) In other words, it is a reasonable estimate of the opportunity cost of capital.

The more cost-effective the implementer, the higher its actual returns lie above expected returns. This should then lead to a greater surplus, stronger financial tailwind, and improved long-term scaling prospects. The reward function should look "as if" to incentivize the implementer to align its objectives with the benefits experienced by the ultimate beneficiaries - so "as if" the challenge was a principal-agent problem.

Prima facie, the payment function achieves this: as described in the Appendix, payments closely approximate the estimated present value of estimated consumption gains. All else equal: the higher the value created by the implementer, the higher the reward. There is an important wrinkle however. We must account for the fact that risk capital providers will be compensated before any residual rewards can be retained by the implementer. (As a risk capital provider cannot obtain ownership over a nonprofit implementer any more than a funder can, we can hardly treat their partnership as one and the same actor.) Given the working capital solution that the implementer independently negotiated: once all claims are settled, what residual rewards can we realistically expect it to retain? 
For illustration, first assume that the payment function was applied to the previous trial, using the data and estimates $^{14}$ from Sedlmayr et al. (2018): $\hat{a}_{0}=45.25, \hat{a}_{m}=29.35, \hat{c}_{m}=3.90, \widehat{m}=22$. This leads to $P_{m}=P_{m_{F}}=P_{m_{C}}\left(\hat{a}_{m}, \hat{c}_{m}\right)=175.18$. Past unit costs per household (excluding the transfer portion which was already reimbursed through payment $P_{0}$ - but including all local and international overhead) were estimated at USD 172.60 per household. ${ }^{15}$ This implies that the implementer would have generated a small return of $0.07 \%$ monthly. As this lies below the negotiated threshold of $0.57 \%$, all of it would have been passed on to the working capital providers (i.e., investors).

To be sure: even if we assume that past outcomes predict future ones, past hypothetical payouts may not equal expected payouts. In forming expectations about the future project, we should account for the fact that impact estimates will be subject to sampling error, and neither the function that makes payments to the implementer nor the function that subtracts the share of the investors is symmetric around the expected values. Let us now assume that outcomes will be generated by the processes $a_{m}=\hat{a}_{m}+\varepsilon_{a_{m}}$ and $c_{m}=$ $\hat{c}_{m}+\varepsilon_{c_{m}}$, where $\varepsilon$ is normally distributed with a mean of zero and a standard deviation of $\hat{\varepsilon}$ (i.e., the respective errors that were associated with point estimates $\hat{a}_{m}$ and $\hat{c}_{m}$ in the previous trial; this assumes, in simplifying fashion, that sampling procedures and therefore sampling error will remain unchanged). The upper left hand side of Figure 5 uses this assumption to simulate combinations of outcomes $a_{m}$ and $c_{m}$, calculating a payment $P_{m}$ for each.

\footnotetext{
${ }^{14} \hat{a}_{0}$ is defined as the UGX amount of the cumulative transfer to the beneficiary household, divided by what the paper defines as the UGX/USD intervention exchange rate. $\hat{a}_{m}=29.35$ is the residual asset effect in the household at the time of the survey, divided by the pooled rate. $\hat{c}_{m}$ is the monthly consumption effect at the household level, divided by the pooled rate.

${ }^{15}$ Derived from the trial by Sedlmayr et al. (2018), this is the weighted programmatic cost of sub-arms A2 and B2, excluding transfers.
} 
Figure 5: Simulation of Outcomes and Payments $\boldsymbol{P}_{\boldsymbol{m}}$
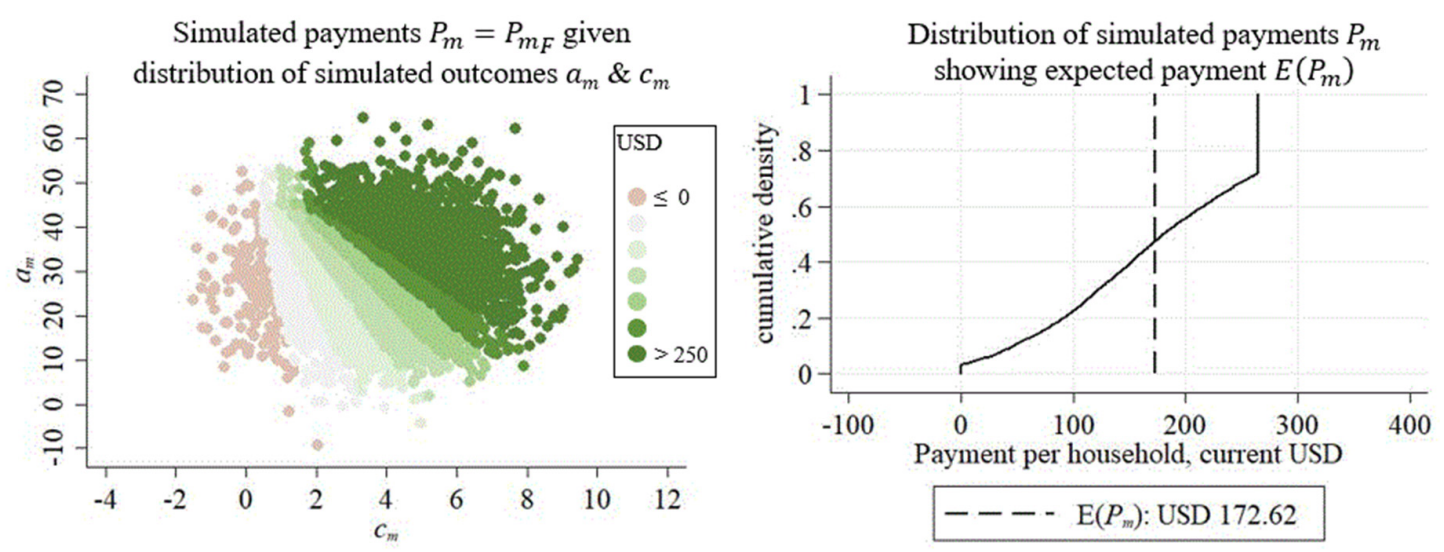

Payment passed on to
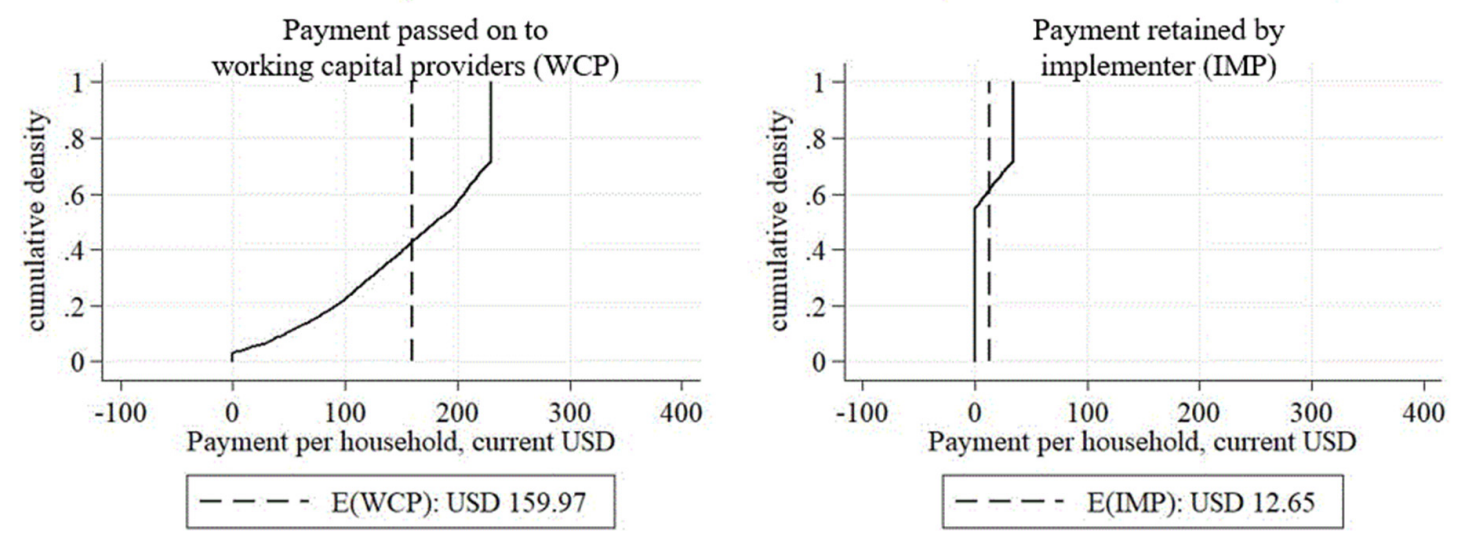

Note: Using data from the previous trial, the chart on the top left displays the distribution of 5,000 simulated combinations of $a_{m}$ and $c_{m}$. Each of the combinations is also color-coded to indicate the associated payment, as displayed in the legend. For a more detailed derivation of this chart, consult the Appendix. The distribution of resulting payments is visualized in simplified form in the chart on the top right, with the expected payment being the average simulated payment. The bottom left and right charts illustrate how the expected payment is split between the investors and the implementer, in each of the simulated scenarios and on average (i.e., in expectation).

The upper right hand side of Figure 5 plots the same distribution of simulated payments in the form of a cumulative density function. We can see that a small share of simulated payments is constrained by the payment floor while a larger of simulated payments is constrained by the payment cap. The probabilityweighted expected payment is therefore reduced below $P_{m}\left(\hat{a}_{m}, \hat{c}_{m}\right)=175.18$ to $E\left(P_{m}\left(a_{m}, c_{m}\right)\right)=$ 172.62. This corresponds almost exactly to the estimated unit costs per household of USD 172.60, and the expected return remains just barely positive. The bottom two charts of Figure 5 show how expected 
payments are split between working capital providers and the implementer. In expectation, the implementer generates a surplus of only USD 12.65 per household. ${ }^{16}$

Summing up: just like the principal-agent argument, the evolutionary argument for PbR requires that implementers have "skin in the game" - so end up in a stronger financial position (and in a better position to propagate) in the case of success than the case of failure. But in the studied case, once investors' absorption of up- and downsides is accounted for, the residual rewards to the implementer are modest. We are reduced to the "attention frame" - the argument that the project draws attention to results - as the most plausible justification for the project.

\section{CONTEXTUALIZED ANALYSIS OF CONCERNS}

\section{Costs}

The project relies on administrative data, a simple validation exercise, and a single household survey. By relying on the validation exercise to quantify $a_{0}$ and on the implementer's targeting data to improve the estimates of $a_{m}$ and $c_{m}$, the project avoids the substantial costs of a baseline survey. Ultimately the optimal number of survey rounds continues to depend on statistical power considerations (McKenzie, 2012), which in turn depend on the scale of the project. It is important for the survey to collect estimates that are not downward biased through the omission of minor and exotic items. This may be achievable through a shortened commodity list design such as that described in Beegle et al. (2012), which collects key

16 The forthcoming evaluation may differ from those in the previous trial for diverse reasons beyond sampling procedures, such as changes in experimental design, estimation strategy, and context. One change that is already foreseeable is the duration of the investment. The project schedule (as illustrated in Figure 3) suggests a duration (i.e., weighted payback period) in the vicinity of 52 months. Given a minimum investment of USD 157.77 in non-cash expenses per household and a $P_{m_{c a p}}$ of USD 265.00, this implies that the maximum achievable return - i.e., that which could be shared between the implementer and the investors in the very best case - is $1.00 \%$ monthly $(12.68 \%$ annually) at most. After returning to investors the full principal, plus a $0.57 \%$ monthly ( $7.00 \%$ annual) return, plus half of the remainder, the highest possible surplus that Village Enterprise can mathematically retain in the future amounts to USD 26.74 per household. 
consumption items and scales to full consumption estimates based on multipliers from more comprehensive local household surveys. Unfortunately, a similar shortcut is not widely accepted for the purpose of asset measurement.

The results-based contract is the single most complex and legally fraught transaction in the entire arrangement, and pooling resources into one outcomes fund allowed for it to be executed once as opposed to three times. As discussed, funders were not involved in the pre-financing of the production process: they effectively focused on creating demand and left it to market forces to supply the needed inputs, including working capital financing.

Recall that a critical working hypothesis was that even a small organization such as Village Enterprise would be able to effectively leverage the funders' commitments. Indeed, less than half a year after the formalization of the challenge, the implementer had indeed raised more working capital than its entire organizational budget in any previous year. The involvement of risk capital providers (i.e., private investors) give the project the central feature of a so-called impact bond. But the responsibility for raising working capital was left exclusively to the implementer, and other project stakeholders did not get involved in pre-financing. This mirrors private sector transactions, as well as a results-based financing tool called the advance market commitment (Berndt et al., 2006). While the Village Enterprise experience suggests that this may be low-cost approach to the origination of impact bonds, we also see that it leaves the implementer to independently negotiate the arrangements that define capital costs, and thereby ultimately define the incentive structure.

The capital costs obtained by the implementer appear favorable: Though the risks associated with the project may be largely uncorrelated with other asset classes and therefore well diversifiable, the negotiated rates do imply a philanthropic subsidy. That said, some form of social calculus appears to apply to a large pool of global financial assets (Bernow, Klempner, \& Magnin, 2017).

\section{Potential for Motivation Crowding}


Assuming that the implementer is intrinsically motivated to perform, is the challenge likely to crowd out this intrinsic motivation? We should consider the mechanism through which motivation crowding is thought to work. It is a behavioral phenomenon that is triggered when a principal's actions are perceived as controlling (Frey, 2017) and cast doubt on the nonpecuniary motives or trustworthiness of the agent (Falk \& Kosfeld, 2006). This control, and the presumed motivation behind it, is thought to lead to a reduction in intrinsic motivation. (For this reason, the adverse performance effects of motivation crowding are sometimes referred to as "hidden costs of control".)

As described in the Background section, the project frames implementers not as morally dubious subordinates to be controlled but as pioneering entrepreneurs to be empowered. Choosing this reinforcement learning frame - as opposed to a performance incentive frame - is entirely consistent with the project's rationale. But it also appears reasonable from a behavioral perspective: one may hypothesize that abandoning the presumption of a mismatch between funder and implementer intentions helps to mitigate crowding effects. ${ }^{17}$

\section{Potential for Gaming}

There are a number of ways in which the implementer could game the system.

\section{Misreporting}

As the implementer collects targeting data, and this targeting data is used as a covariate in the later evaluation, the data could become tainted. This is avoided by assuring that data are shared with the independent evaluator prior to the randomized assignment (where it also serves as a stratification variable). In principle, the implementer could be tempted to manipulate respondents by coaching them to inflate or

${ }^{17}$ More generally, if formalized conditionality is perceived as ordinary in institutional transactions while individuals rely more frequently on trust-based transactions, institutional agents (such as the implementer in question) should be less susceptible to motivation crowding from $\mathrm{PbR}$ than individual agents (such as the experimental subjects in the literature on motivation crowding). 
deflate survey responses depending on their assignment. To avoid this, the implementer is barred from announcing the future independent survey to any participant, and from interacting with the control group after the targeting exercise. The evaluator collects consent at the survey stage ${ }^{18}$ and probes for breaches of protocol. There is a clause in the funding agreement that allows for payment to be withheld if breaches are established.

\section{Re-Balancing of Activities}

Might the implementer re-balance activities to focus only on what is measured? Consumption is a credible indicator of living standards among the poor and a less noisy alternative to income, partly because it can be collected through surveys with reasonably high accuracy (Deaton, 1997; Meyer \& Sullivan, 2003) and partly because it is subject to consumption smoothing. It is an appropriate definition of the ultimate outcome objective.

To estimate the present value of permanent consumption, modeling assumptions are required. It was assumed that trends in consumption impacts are proportional to trends in assets impacts, which is consistent with the organization's theory of change: that the maintenance of microenterprise assets defines households' long-term poverty reduction. This model can however collapse if we venture beyond the organization's theory of change. For instance, the implementer could game the system in principle by encouraging participants to dissave some tangible assets around the time of survey measurement so that inflated consumption gains temporarily materialize. The implementer could also discourage households from investing in intangibles that cannot lead to an increased consumption flow within the measurement period (say, investments in the education of young children).

\footnotetext{
${ }^{18}$ Minimizing the perceived association of the implementer and the independent evaluator also reduces the risk that participants interpret the independent survey as an intervention targeting exercise and independently misreport their economic status for that reason.
} 


\section{Under-Investment}

As was illustrated in Figure 5, effects will in fact be measured with error, which may well make the payment bounds binding. What we have not considered to date is that this could trigger incentive processes that distort the investment decision in the first place. To avoid detailed assumptions about the implementer's production function, let us focus on the basic intuition. Assume that the implementer had not approached investors for working capital and had neither invested in cash transfers nor in intangible extensions, and that the true impact of its activities was therefore zero. Let us call this the "Minimum-Effort" strategy. The right hand side of Figure 6 simulates the outcomes of this strategy. We can see that the lower payment bound is now very likely to be binding: in 50\% of simulations, it "insures" the implementer against negative outcome measures. Meanwhile, in the $50 \%$ of cases in which sampling error goes in the implementer's favor, a payment is made although no true effect could have materialized. As already illustrated in Figure 5, the expected net payout to the implementer in a Business-as-Usual strategy amounts to only USD 12.65 per household once the investor has been compensated. But as no investors must be compensated in the Minimum-Effort strategy, the implementer could expect to retain the full payment of USD 46.54 quantified in Figure 6. 


\section{Figure 6: Simulation of Payments under Alternative Implementation Strategies}
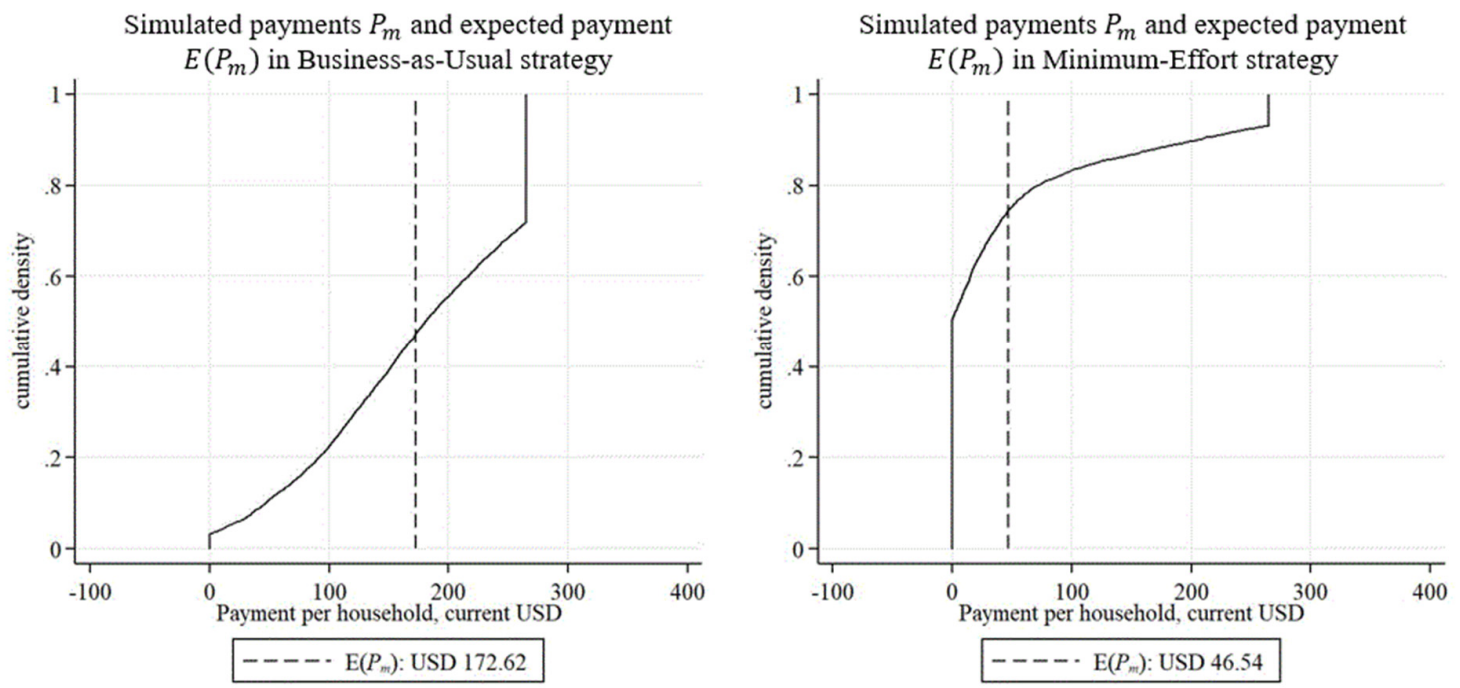

Note: Using data from the previous trial, the chart on the left displays the distribution of payments resulting from of 5,000 simulations of the processes $a_{m}=\hat{a}_{m}+\varepsilon_{a_{m}}$ and $c_{m}=\hat{c}_{m}+\varepsilon_{c_{m}}$, where $\varepsilon$ is normally distributed with a mean of zero and a standard deviation of $\hat{\varepsilon}$ (i.e., the respective errors that were associated with point estimates $\hat{a}_{m}$ and $\hat{c}_{m}$ in the previous trial). The chart on the right displays the distribution of payments resulting from of 5,000 simulations of the processes $a_{m}=0+\varepsilon_{a_{m}}$ and $c_{m}=0+\varepsilon_{c_{m}}$.

More generally, the introduction of sampling error raises expected payments when true impacts are low and reduces expected payments when true impacts are high. The more the implementer invests, the lower the insurance value of the payment floor and the higher the disincentive generated by the payment cap.

\section{Over-Investment}

An incentive in the opposite direction could appear if we take reputational considerations into account. An implementer who wishes to build a reputation of cost-effectiveness could be tempted to provide the project with hidden subsidies, e.g. in the form of indirect support not accounted for in overhead budgets, that remain invisible to the other parties involved. This concern is elevated in the case of nonprofit implementers who can allocate any unrestricted grant funds as they please. It could render transaction data inefficient, underestimating the true social cost of achieving the outcomes. This appears difficult to avoid, or even measure, in the short run: the transparent costing of managerial and similar intangible contributions is a tall task. 


\section{$\underline{\text { SUMMARY }}$}

The central policy challenge at hand does not involve information asymmetries, but fundamental knowledge gaps that make it difficult to generalize from available pilot evidence to projections of impact at scale. The potential contribution of $\mathrm{PbR}$ is its evolutionary justification: it has the potential to introduce a feedback mechanism between the outcomes achieved and the implementer's financial standing. If funders cannot confidently grasp the necessary conditions for impact, appraise their existence and role in new settings, and generalize from evidence that is available ex ante, they might instead leave it to the reinforcement effects of $\mathrm{PbR}$ to "learn" on their behalf by promoting propagation where success happens to materialize. For this process to function, payments should be tied to the ultimate outcome objective, "as if" to incentivize performance. Prima facie, the studied reward function achieves this.

However, working capital requirements led the implementer to seek a financing solution that transferred the incidence of most risks and rewards to third parties, thereby weakening the link between the outcomes achieved and the rewards retained by the implementer. Further, the implementer is a nonprofit that could subsidize its activities in diverse ways not governed by the laws of business economics: e.g., by obtaining non-market financing conditions or other forms of subsidies. The evolutionary justification for $\mathrm{PbR}$ would seem stronger if the implementers were strictly for-profits competing in open markets. That said, if we shift to the assumption of self-interest, other problems become pressing. A rogue implementer could take advantage sampling error to game the system, privatizing upsides and socializing downsides. In the studied arrangement, tight payment bounds make "investing little and hoping for the best" a lucrative short-term strategy in expectation. The concern did not end up materializing because the implementer's independent negotiations with investors led to an agreement that mandates a minimum investment per beneficiary household. But to mitigate this issue in any future iterations, payment bounds should be expanded. A reduction in sampling error would also help; as this can be accomplished with larger samples, the concern tends to fall somewhat with greater scale. 
We argued that another potential advantage of $\mathrm{PbR}$ is its tendency to force funders to pay adequate attention to the opportunity cost of capital, and to force implementers to align their actions with a quest for costeffectiveness. While our case format cannot assess this argument comprehensively, it does illustrate in detail how this process can function: funders consult available evidence to establish the opportunity cost of capital; use this to shape their willingness to pay for outcomes; commit and escrow funds; and leave it to implementers to deliver. This speaks to an ongoing debate in the aid effectiveness space. So-called cash benchmarking establishes to what degree different interventions are able to outperform the impacts of costequivalent unconditional cash transfers (Center for Global Development, 2018). But in the long run, the most appropriate benchmark is not the estimated impact of some arbitrary intervention - even one that may appear as "generic" as plain cash - but the estimated impact of the best alternative use of capital. Further, the appropriate benchmark for development interventions is not one impact estimate at one arbitrary point in time, but an economic rate of return that accounts for long-term impact patterns. The studied payment function puts these principles front and center.

The idea of using $\mathrm{PbR}$ as a tool to help overcome knowledge gaps is a systemic one whose promise can unfold only through iteration and institutionalization. If we assume that donors' outcome challenge to the implementer will be expanded beyond the funded seven cohorts, and that the capital market conditions will remain as they have been, then we have the makings of a mechanism that would allow the implementer to scale up indefinitely, so long as impacts do not deteriorate. This is one potential answer to the challenge of scaling up graduation with fidelity. Over time, funders could challenge further organizations and adjust the required rates of return to account for improved insights about the opportunity cost of capital; in the long run, only the most cost-effective approaches would remain economically viable, whether or not they still resemble graduation. Required rates of return could be adjusted to allow for different valuations in different populations; "rate cards" might show donors' willingness to pay by outcome and setting. For such visions have a chance at realization, a number of kinks need to be worked out. In particular, reward functions 
should account for how funders, implementers, and working capital providers share the risks associated with sampling error. 


\section{APPENDIX: DERIVING PAYMENT $P_{M}$}

Let us first derive that payment which, if made in period $m$, aligns the present value of all payments exactly with the present value of consumption impact. Let us call this the unedited payment function $P_{m_{U}}$ :

$$
P_{0}+\frac{P_{m_{U}}}{(1+\beta)^{m}}=\sum_{i=1}^{\infty} c_{i}\left(\frac{1}{1+\beta}\right)^{i}
$$

Because of measurement constraints, consumption is only measured once in period $m$ and expanded across time using growth rate $g$ :

$$
\text { (XII) } \quad P_{0}+\frac{P_{m_{U}}}{(1+\beta)^{m}}=c_{m} \sum_{i=1}^{\infty}(1+g)^{i-m}\left(\frac{1}{1+\beta}\right)^{i}
$$

This implies that the representative participant experiences positive incremental consumption as early as period 1. The growth of consumption impact is assumed to follow that of asset impact with constant returns to scale, growing (or declining) at the same rate into perpetuity. In period $m$, the trajectory of monthly consumption impact crosses level $c_{m}$. For later simplification, we now separate the consumption stream into that portion which materializes in periods 1 through $m$ and that which materializes in periods $m+1$ through $\infty$ :

(XIII) $P_{0}+\frac{P_{m_{U}}}{(1+\beta)^{m}}=c_{m} \sum_{j=1}^{m}(1+g)^{j-m}\left(\frac{1}{1+\beta}\right)^{j}+c_{m} \sum_{k=m+1}^{\infty}(1+g)^{k-m}\left(\frac{1}{1+\beta}\right)^{k}$

We know from Equation II that $P_{0}$ provides the implementer with the value $a_{0}$, so we substitute:

$$
\text { (XIV) } P_{m_{U}}=-a_{0}(1+\beta)^{m}+c_{m} \sum_{j=1}^{m}\left(\frac{1+g}{1+\beta}\right)^{j-m}+c_{m} \sum_{k=\mathrm{m}+1}^{\infty}\left(\frac{1+g}{1+\beta}\right)^{k-m}
$$

We can simplify to:

(XV) $\quad P_{m_{U}}=-a_{0}(1+\beta)^{m}+c_{m} \sum_{j=1}^{m}\left(\frac{1+g}{1+\beta}\right)^{j-m}+c_{m} \sum_{k=1}^{\infty}\left(\frac{1+g}{1+\beta}\right)^{k}$ 
The third term on the right hand side represents an infinite-horizon valuation problem (Gordon \& Shapiro, 1956). We can solve it as follows. Given that:

(XVI) $\quad \sum_{k=1}^{\infty} \mu^{k}=\mu+\mu^{2}+\cdots+\mu^{\infty}$

And:

(XVII) $\mu \sum_{k=1}^{\infty} \mu^{k}=\mu^{2}+\cdots+\mu^{\infty}$

we can see that if $-1<\mu<1$, the following holds:

$$
(\mathrm{XVIII}) \sum_{\mathrm{k}=1}^{\infty} \mu^{k}-\mu \sum_{k=1}^{\infty} \mu^{k}=\mu
$$

Re-arranging:

(XIX) $\quad \sum_{k=1}^{\infty} \mu^{k}=\frac{\mu}{1-\mu}$

Therefore, under the assumption that $-1<\mu=\frac{1+g}{1+\beta}<1$, we know that $\sum_{k=1}^{\infty}\left(\frac{1+g}{1+\beta}\right)^{k}=\frac{\frac{1+g}{1+\beta}}{1-\frac{1+g}{1+\beta}}=\frac{1+g}{\beta-g}$ and we can simplify to (XVI) to

$$
\text { (XX) } \quad P_{m_{U}}=-a_{0}(1+\beta)^{m}+c_{m} \sum_{j=1}^{m}\left(\frac{1+g}{1+\beta}\right)^{j-m}+c_{m} \frac{1+g}{\beta-g}
$$

$P_{m_{U}}$ aligns the present value of all payments exactly with the estimated present value of estimated consumption gains.

There are a few discontents with $P_{m_{U}}$. First, it can give rise to outlier payments - extreme (potentially infinite) liabilities for either payers or implementers in case of extremely positive or negative results. 
Second, it is undefined for extreme values of $a_{m} \cdot{ }^{19}$ Third, it has an unwelcome property: for low estimates of $a_{m}$, a further reduction in $a_{m}$ results in higher $P_{m_{U}}$. (This emanates from the assumptions about the link between asset growth and consumption growth, which in the short run are not as benign as they may appear. ${ }^{20}$ ) Fourth, Equation $X X$ is complex and not easy to contract upon.

Equation III assumes that for the duration of the project - so in periods 1 through $m$ - rates $g$ and $\beta$ are zero. This simplifies the first two terms of Equation $X X$, which are no longer subject to discount nor growth rates. Further, by introducing scenarios A and B, Equation III defines payments for extreme values of $a_{m}$. The result is an edited payment function labeled the edited payment function $P_{m_{E}}-$ a better behaved and fully defined alternative to $P_{m_{U}}$. It is defined as follows:

$$
\begin{array}{rlll} 
& \text { IF } a_{m} \leq 0 & \rightarrow \text { THEN } P_{m_{E}}=P_{m_{A}} \\
\text { (XXI) IF } a_{m} \geq a_{0} & \rightarrow \text { THEN } P_{m_{E}}=P_{m_{B}} \\
\text { IF } a_{0}>a_{m}>0 & \rightarrow \text { THEN } P_{m_{E}}=P_{m_{C}}
\end{array}
$$

For a definition of $P_{m_{A}}, P_{m_{B}}$, and $P_{m_{C}}$, consult Equations $I V-I X$. As $P_{m_{E}}$ can continue to result in outlier payments, Equation $X$ adds bounds that were negotiated by the funders and the implementer to remove tail risks, resulting in the final payment function $P_{m_{F}}$, as described in Equation $X$.

19 This is because of the assumptions that needed to be made in the process of defining a finite $P_{m_{U}}$; namely, that $a_{m}>0$ and that $-1<\frac{1+g}{\beta-g}<1$.

${ }^{20}$ As discussed, the project assumes that all assets are productively invested and that their returns are constant to scale and consumed, so that $g$ (which is derived from asset growth rates) can approximate growth rates in consumption. So in Equation XX, all else equal, a lower $a_{m}$ (and lower $g$ ), yields lower projections of future consumption (beyond period $m$ ) but higher estimates of accumulated consumption (in periods 1 through $m$ ). For very low levels of $a_{m}$, the latter effect outweighs the former, so a further reduction in $a_{m}$ increases the implied net present value of consumption and therefore payments. 


\section{BIBLIOGRAPHY}

Andrews, M., Pritchett, L., \& Woolcock, M. (2013). Escaping Capability Traps Through Problem Driven Iterative Adaptation (PDIA). World Development, 51, 234-244.

Ashraf, N., Bandiera, O., \& Jack, B. K. (2014). No Margin, no Mission? A Field Experiment on Incentives for Public Service Delivery. Journal of Public Economics, 120, 1-17.

Bandiera, O., Burgess, R., Das, N., Gulesci, S., Rasul, I., \& Sulaiman, M. (2017). Labor Markets and Poverty in Village Economies. Quarterly Journal of Economics, 811-870.

Banerjee, A., Deaton, A., Lustig, N., Rogoff, K., \& Hsu, E. (2006). An Evaluation of World Bank Research, 1998 - 2005. Washington, DC.

Banerjee, A., \& Duflo, E. (2011). Poor Economics: A Radical Rethinking of the Way to Fight Global Poverty. New York: PublicAffairs.

Banerjee, A., Duflo, E., Goldberg, N., Karlan, D., Osei, R., Parienté, W., ... Udry, C. (2015). A Multifaceted Program Causes Lasting Progress for the Very Poor: Evidence from Six Countries. Science, 348(6236), 1260799.

Barder, O. (2012). Complexity, Adaptation, and Results. Retrieved from https://web.archive.org/web/20190205141316/https://www.cgdev.org/blog/complexity-adaptationand-results

Barto, A., \& Sutton, R. (1998). Reinforcement Learning: An Introduction. Cambridge: MIT Press.

Bates, M. A., \& Glennerster, R. (2017). The Generalizability Puzzle. Stanford Social Innovation Review, (Summer).

Batson, C. D., \& Shaw, L. L. (1991). Evidence for Altruism: Toward a Pluralism of Prosocial Motives, $2(2), 107-122$.

Beegle, K., De Weerdt, J., Friedman, J., \& Gibson, J. (2012). Methods of Household Consumption Measurement through Surveys: Experimental results from Tanzania. Journal of Development Economics, 98(1), 3-18.

Beinhocker, E. D. (2007). The Origin of Wealth. Cambridge, MA: Harvard Business Review Press.

Bénabou, R., \& Tirole, J. (2006). Incentives and Prosocial Behavior. American Economic Review, 96(5), $1652-1678$.

Berndt, B. E. R., Glennerster, R., Kremer, M. R., Lee, J., Weizsacker, G., Williams, H., \& Levine, R. (2006). Advance Market Commitments for Vaccines Against Neglected Diseases : Estimating Costs and Effectiveness. Health Policy, (98), 1-43.

Bernow, S., Klempner, B., \& Magnin, C. (2017). From 'Why' to 'Why Not': Sustainable Investing as the New Normal. Retrieved from https://web.archive.org/web/20190210020101/https://www.mckinsey.com/industries/private-equityand-principal-investors/our-insights/from-why-to-why-not-sustainable-investing-as-the-new-normal 
Blattman, C., \& Niehaus, P. (2014). Show Them the Money: Why Giving Cash Helps Alleviate Poverty. Foreign Affairs, 93(3).

Bold, T., Kimenyi, M., Mwabu, G., Ng'ang'a, A., \& Sandefur, J. (2013). Scaling-up What Works: Experimental Evidence on External Validity in Kenyan Education (Working Paper Series No. 321). Center for Global Development.

Brodeur, A., Sangnier, M., Lé, M., Sangnier, M., \& Zylberberg, Y. (2016). Star Wars: The Empirics Strike Back. American Economic Journal: Applied Economics, 8(1), 0-37.

Callen, M., Khan, A., Khwaja, A., \& Liaqat, A. (n.d.). How do Civil Servants Update? Constraints to Evidence Based Decision Making. Forthcoming.

Campbell, D. T. (1979). Assessing the Impact of Planned Social Change. Evaluation and Program Planning, 2(1), 67-90.

Carter, E., \& Whitworth, A. (2015). Creaming and Parking in Quasi-Marketised Welfare-to-Work Schemes: Designed Out Of or Designed In to the UK Work Programme? Journal of Social Policy, 44(2).

Cartwright, N., \& Hardie, J. (2012). Evidence-Based Policy: A Practical Guide to Doing It Better. Oxford University Press USA.

Center for Global Development. (2018). More Results for the Money: Cash Benchmarking at USAID. Retrieved from https://web.archive.org/web/20190110181647/https://www.cgdev.org/blog/moreresults-money-cash-benchmarking-usaid

Chan, A. W., Hrobjartsson, A., Haahr, M. T., Gotzsche, P. C., \& Altman, D. G. (2004). Empirical Evidence for Selective Reporting of Outcomes in Randomized Trials: Comparison of Protocols to Published Articles. JAMA : The Journal of the American Medical Association, 291(20), 2457-2465.

Clist, P. (2016). Payment by Results in Development Aid: All that Glitters is not Gold. World Bank Research Observer, 31(2), 290-313.

Courty, P., \& Marschke, G. (2008). A General Test for Distortions in Performance Measures. Review of Economics and Statistics, 90(3), 428-441.

Dawkins, R. (1976). The Selfish Gene. Oxford: Oxford University Press.

Deaton, A. (1997). The Analysis of Household Surveys: A Microeconometric Approach to Development Policy. Washington DC: World Bank Publishing Group.

Deaton, A. (2010). Instruments, Randomization, and Learning about Development. Journal of Economic Literature, 48(2), 424-455.

Dixit, A. (2002). Incentives and Organizations in the Public Sector: An Interpretative Review. The Journal of Human Resources, 3743(18), 696-727.

Eldridge, M., \& Tekolste, R. (2016). Results-Based Financing Approaches: Observations for Pay for Success from International Experiences (Urban Institute Working Paper). 
Falk, A., \& Kosfeld, M. (2006). The Hidden Costs of Control. The American Economic Review, 96(5), $1611-1630$.

Fehr, E., \& Fischbacher, U. (2003). The Nature of Human Altruism. Nature, 425(6960), 785-791.

Floyd, D. (2017). Briefing on Social Impact Bonds Social Impact Bonds: An Overview of the Global Market for Commissioners and Policymakers (Centre for Public Impact).

Fraser, A., McHugh, N., \& Warner, M. (2019). Widening Perspectives on Social Impact Bonds. Journal of Economic Policy Reform.

Frey, B. S. (1997). Not Just for the Money: an Economic Theory of Personal Motivation. Wiley Online Library, 80, 77-78.

Frey, B. S. (2017). Policy consequences of Pay-for-Performance and Crowding-Out. Journal of Behavioral Economics for Policy, 1(1), 55-59.

Friedman, M. (1953). The Methodology of Positive Economics. In Essays in Positive Economics (pp. 138). Chicago: University of Chicago Press.

Gartlehner, G., Hansen, R., Nissman, D., Lohr, K., \& Carey, T. S. (2006). Criteria for Distinguishing Effectiveness From Efficacy Trials in Systematic Reviews. Agency for Healthcare Research \& Quality, (12), 1-28.

Gneezy, U., \& Rustichini, A. (2000). A Fine is a Price. The Journal of Legal Studies, 29(1), 1-17.

Gong, Y., Shenkar, O., Luo, Y., \& Nyaw, M.-K. (2007). Do Multiple Parents Help or Hinder International Joint Venture Performance? Strategic Management Journal, 28(10), 1021-1034.

Goodhart, C. (1975). Problems of Monetary Management: The U.K. Experience (Papers in Monetary Economics, Reserve Bank of Australia).

Gordon, M. J., \& Shapiro, E. (1956). Capital Equipment Analysis: The Required Rate of Profit. Management Science, 3(1), 102-110.

Holmstrom, B., \& Milgrom, P. (1991). Multitask Principal-Agent Analyses: Incentive Contracts, Asset Ownership, and Job Design. Journal of Law, Economics, and Organization, 7(special), 24-52.

Instiglio. (2018). Design Memo: Village Enterprise Development Impact Bond. Bogota.

Ioannidis, J. P. A. (2005). Why Most Published Research Findings are False. PLoS Medicine, 2(8), 06960701.

Jacob, B. A., \& Levitt, S. D. (2003). Rotten Apples: An Investigation of the Prevalence and Predictors of Teacher Cheating. Quarterly Journal of Economics, 118(3), 843-877.

Jensen, R. (2010). The (Perceived) Returns to Education and the Demand for Schooling. Quarterly Journal of Economics, 125(2), 515-548.

Lazear, E. P. (2003). Teacher incentives. Swedish Economic Policy Review, 10, 179-214. 
Lynch, A. (1996). Thought Contagion: How Belief Spreads Through Society. New York: Basic Books.

Mayr, E. (1961). Cause and Effect in Biology. Science, 134(3489), 1501-1506.

McHugh, N., Sinclair, S., Roy, M., Donaldson, C., \& Huckfield, L. (2013). Social Impact Bonds: A Wolf in Sheep's Clothing? Journal of Poverty and Social Justice, 21(3).

McKenzie, D. (2012). Beyond Baseline and Follow-Up: The Case for More T in Experiments. Journal of Development Economics, 99(2), 210-221.

Meyer, B. D., \& Sullivan, J. X. (2003). Measuring the Well-Being of the Poor Using Income and Consumption (NBER Working Paper No. 9760).

Nelson, R. R., \& Winter, S. G. (1982). An Evolutionary Theory of Economic Change. Cambridge MA Belknap (Vol. 93). Cambridge: Belknap Press.

Perakis, R., \& Savedoff, W. (2015). Does Results-Based Aid Change Anything? Pecuniary Interests, Attention, Accountability and Discretion in Four Case Studies (No. Working Paper 52). Washington, DC.

Polanyi, M. (1966). The Tacit Dimension. Chicago: University of Chicago Press.

Savedoff, W., Perakis, R., \& Schwanke, B. (2016). Shifting the Foreign Aid Paradigm - Paying for Outcomes. The White House and the World.

Schumpeter, J. (1942). Capitalism, Socialism and Democracy. London: Routledge.

Sedlmayr, R., Shah, A., \& Sulaiman, M. (2018). Cash-Plus: Poverty Impacts of Transfer-Based Intervention Alternatives (CSAE Working Paper No. WPS/2017-15-2).

Shapiro, J. (2017). Benchmarking Development Programs: A Preference-Based Approach.

Social Finance. (2019). Impact Bond Global Database. London: Social Finance. Retrieved from https://web.archive.org/web/20190810162752/https://sibdatabase.socialfinance.org.uk/

Vann, M. G. (2003). Of Rats, Rice, and Race: The Great Hanoi Rat Massacre, an Episode in French Colonial History. French Colonial History, 4(1), 191-203.

Williams, M. J. (2017). External Validity and Policy Adaptation: From Impact Evaluation to Policy Design (BSG Working Paper No. BSG-WP-2017/019). 